\title{
Carcinogenic Fluorinated Hydrocarbon
}

National Cancer Institute

\section{Source}

National Cancer Institute. Carcinogenic Fluorinated Hydrocarbon. NCI Thesaurus. Code C45391.

A hydrocarbon compound consisting of carbons with one or more fluoride atom incorporated in its structure that can increase the risk of human cancer. ( $\mathrm{NCI05)}$ 